\title{
In vitro and In vivo Assessment of Pi3K $\gamma$ Inhibitors for Anti-Inflammatory Indications: Challenges of Selectivity over Pi3Ka
}

\author{
David Lamb*, Graham Lunn, Mark O’Reilly, Cheryl Butler and lain Kilty
}

Pfizer Global Research and Development, Sandwich Laboratories, United Kingdom

\begin{abstract}
Class 1 PI3Ks are a growing area of interest as pharmacological targets across a number of disease mechanisms. We have assessed the feasibility of developing selective PI3Kgamma inhibitors based upon the ATP-binding hinge site. Following full file screening, 8800 analogues representing 25 chemotypes were further analysed across a panel of PI3K enzymes and cellular assays. Despite this we did not identify a series of compounds which possessed all required criteria of potency, selectivity, metabolic stability and solubility. We profiled the best 3 compounds in vivo to assess their anti-inflammatory efficacy versus PI3Kalpha driven perturbations in glucose/insulin homeostasis. Each compound dose-dependently inhibited LPS elicited pulmonary neutrophilia in rat with a marginal therapeutic index over a subsequent increase in glucose and insulin elevation. In our opinion these studies provide no evidence of a divergence from enzyme selectivity to an in vivo therapeutic index over insulin and glucose perturbations and therefore there is no evidence to suggest ATP competitive hinge binding site PI3Kgamma inhibitors will afford sufficient in vivo TI worthy of clinical progression for inflammatory indications.
\end{abstract}

\section{Introduction}

Phosphatidylinositol-3 kinases (PI3Ks) are a family of lipid-kinases whose activity is central to a plethora of cellular signalling pathways, and therefore ultimately to the maintenance of physiological homeostasis. Specifically, PI3Ks belonging to the class 1 group have been linked to a number of patho-physiologies of key interest to pharmaceutical companies, such as: cancer, rheumatoid arthritis, cardiovascular disease and respiratory disease $[1,2]$. This class 1 group of PI3Ks contain four isoforms $(\alpha, \beta, \gamma$ and $\delta)$ that are activated upon ligation of particular cell-surface receptors which can subsequently generate a diverse range of cellular activities, including: proliferation, differentiation, adhesion, migration, apoptosis and phagocytosis $[3,4]$. Of particular note, the $\gamma$ and $\delta$ isoforms are a growing interest in the pharmaceutical arena due to the increasing evidence of their role in inflammatory diseases together with their largely haematopoietic-restricted tissue distribution that may ultimately afford more acceptable safety toleration over the more ubiquitously expressed $\alpha$ and $\beta$ isoforms [5]. Indeed, to date selective and specific PI3dK inhibitors have reached Phase II clinical trials for leukaemic pathologies however, to our knowledge, no PI3Kgamma specific compounds have yet been taken to clinical trials [6]. Therefore, our aim was to identify a PI3Kgamma specific inhibitor, which had an acceptable therapeutic index over glucose and insulin elevation.

Our key question was whether the inherent difference between the ATP binding sites of PI3Kgamma and PI3Kalpha, could enable an inhibitor to be found that was selective enough between these two isoforms to provide robust efficacy from inhibition of PI3Kgamma, but which possessed a therapeutic window over glucose and insulin elevation driven by PI3Kalpha inhibition [7]. As such, we wished to understand the translation of human enzyme selectivity through to in vivo efficacy and safety in a suitable animal model, as measured by inhibition of inhaled LPS induced rat lung neutrophilia, and blood insulin and glucose levels.

Various publications (for example [8,9]) have suggested a degree of selectivity of ligands between these key isoforms; in some cases the $\mathrm{IC}_{50}$ 's compared are derived from assays using different concentrations of ATP. We were keen to investigate the selectivity of compounds across the Pi3K isoforms using the same concentration of ATP in assays to provide a fair test of selectivity. Described in this paper is a set of 3 compounds of up to 6 fold selectivity, which had good pharmacokinetic parameters enabling a full dose response to be explored in vivo. This tool set enabled assessment of the translation of in vitro selectivity to in vivo outcomes.

\section{Materials and Methods}

\section{Reagents}

PI3K HTRF ${ }^{\mathrm{TM}}$ Assay (Millipore). Baculovirus expressed, N-terminally-HIS-tagged PI3Ka (DU1468), PI3K $\beta$ (DU5926), PI3K $\gamma$ (DU1747) and PI3K (DU8329) isoforms were sourced from the Division of Signal Transduction Therapy (University of Dundee), coexpressed with the regulatory subunit p85 for the Class1a isoforms. The following reagents were purchased from Sigma unless otherwise stated: recombinant Human IL-8 (Peprotech 200-08M), ammonium chloride (\#09711), potassium bicarbonate (\#60339), BD CytoFix (BD Biosciences \#554655), bovine serum albumin (BSA, fraction V, low endotoxin (\#A9306), D-glucose (Sigma \#G6152), Dimethyl sulphoxide (\#41639), Dulbecco's PBS (\#D8537), ethylenediaminetetraacetic acid (\#E4884), Hanks Balance Salt Solution with $\mathrm{NaHCO}_{3}$, without phenol red (\#H8264), HBSS without phenol red, $\mathrm{CaCl}_{2}$ and $\mathrm{MgSO}_{4}$ (\# H6648).

\section{PI3K enzyme HTRF ${ }^{\mathrm{TM}}$ assays}

Protocol was as per manufacturer's instructions. Final ATP concentration used in all 4 enzyme assays was $20 \mathrm{uM}$.

\section{IL-8 stimulated human and rat neutrophil shape-change assay}

Peripheral venous blood was collected from healthy volunteers (non-medication, non-smoking) of either sex, or from rats, into $2.7 \%$ EDTA ( $1 \mathrm{ml}$ per $10 \mathrm{ml}$ of blood). Red blood cells were lysed using an ammonium chloride lysis protocol. Briefly $10 \mathrm{mls}$ of blood was added to $40 \mathrm{ml} 1 \mathrm{x}$ lysis solution, mixed by inversion and incubated at room temperature for 5 minutes. Lysed blood was centrifuged at $200 \mathrm{~g}$ for 5 minutes at room temperature and the cell pellet washed twice with

*Corresponding author: David Lamb, Pfizer Global Research and Development, Sandwich Laboratories, Ramsgate Road, Sandwich, Kent, CT13 9NJ, United Kingdom, Tel: +49-7351-54141403; Fax: 49-7351- 5498674; E-mail: david.lamb@boehringer-ingelheim.com

Received March 16, 2013; Accepted September 24, 2013; Published September 26, 2013

Citation: Lamb D, Lunn G, O'Reilly M, Butler C, Kilty I (2013) In vitro and In vivo Assessment of $\mathrm{Pi} 3 \mathrm{~K} \gamma$ Inhibitors for Anti-Inflammatory Indications: Challenges of Selectivity over Pi3Ka. J Pulm Respir Med 3: 157. doi:10.4172/2161-105X. 1000157

Copyright: $\odot 2013$ Lamb D, et al. This is an open-access article distributed under the terms of the Creative Commons Attribution License, which permits unrestricted use, distribution, and reproduction in any medium, provided the original author and source are credited. 
Dulbecco's PBS at $200 \mathrm{~g}$ for 5 minutes room temperature. The white blood cell pellet was resuspended into $8 \mathrm{ml}$ assay buffer per $10 \mathrm{ml}$ of initial blood volume. $80 \mu \mathrm{l}$ of the lysed blood cell preparation were pippeted into wells of a 96 -well polypropylene plate and incubated at $37^{\circ} \mathrm{C} / 5 \% \mathrm{CO}_{2}$ for 15 mins. Subsequently, 10 ul of diluted IL-8 was added to all compound treated wells and stimulation control wells or assay buffer for the basal control wells and incubated at $37^{\circ} \mathrm{C}$ for 15 minutes. $100 \mu \mathrm{l}$ of ice-cold BD Cytofix was added to all wells to fix cells and read immediately on a Beckman coulter FC500 or BD Biosciences Canto II flow cytometer. The Forward scatter (FSC) data was captured and analysed using the FC500 MXP software. Neutrophils were gated according to granularity on the side scatter axis and the change in cell size indicated via the mean FSC of the population. Data exported into Excel and analysed using LabStats.

\section{Rat LPS-induced lung-neutrophila model}

Each compound was prepared in gavage vehicle $(0.5 \% \mathrm{w} / \mathrm{v}$ Methylcellulose $/ 0.1 \%$ w/v Tween $80, \mathrm{pH}$ range 6.5-7.5), with the suspension undergoing continuous rolling at $4^{\circ} \mathrm{C}$ until used. A number of different concentrations were prepared so that a $10 \mathrm{ml} / \mathrm{kg}$ dose volume resulted in doses of $0,1,3,10,30,100,300,1000$ and $3000 \mathrm{mg} / \mathrm{kg}$ being administered. A suspension of Prednisolone was also prepared in the same manner, so that a dose of $10 \mathrm{mg} / \mathrm{kg}$ was administered. Sprague-Dawley rats (male, aged approximately 6 weeks) were used in this study, the animals kept in a room with controlled lighting (lights on $06: 00-18: 00)$ and temperature maintained at $21^{\circ} \mathrm{C}-23^{\circ} \mathrm{C}$. Water and rat chow was available ad libitum. Compounds were dosed 1 hour before intratracheal LPS challenge. Bronchoalveolar lavage (BAL) was performed 5 hours post-LPS-challenge. For administration of the LPS-challenge, animals were anaesthetized using isoflurane $(5 \%$ in $95 \%$ oxygen) introduced at a rate of 3 liters/min and scavenged at a rate of 35 litres/min until consciousness was lost (approximately 1-2 minutes). Once anaesthetized, rats were hung by their incisors from a support so that their body weight was still supported by their rear leg. The jaws were opened and the tongue moved to one side so that the vocal chords could be viewed using an otoscope. Using a $100 \mu \mathrm{l}$ Hamilton syringe with a custom made needle $(22 \mathrm{G}, 10 \mathrm{~cm}$, blunt point), the LPS (100 $\mathrm{ng} / 100 \mu \mathrm{l}$ per rat) or saline (100 $\mu \mathrm{l}$ per rat) was injected directly into the trachea. The rats were placed on a heated pad in a supine position to allow recovery from the anaesthesia then returned to their cage.

Five hours post LPS-challenge; animals were euthanized by intraperitoneal injection of pentobarbital sodium at $150 \mathrm{mg} / \mathrm{kg}$. Blood was sampled through cardiac puncture for determination of insulin and glucose levels. Blood samples for insulin assay were collected into tubes containing protease inhibitors. The lungs were lavaged in situ with four $2.5 \mathrm{ml}$ aliquots of phosphate buffered saline containing 2.6 mM EDTA. The BAL fluid was kept on ice until processing. BAL fluid was centrifuged at $300 \mathrm{~g}$ for $10 \mathrm{~min}$. The cell pellets were resuspended in PBS. Total cell counts were determined using a grid hemacytometer using trypan blue exclusion. Differential cell counts were determined on cytospin-prepared slides that were stained with a modified Wright-Giemsa method (Sigma Aldrich (MO, USA)) according to the manufacturer's instructions. At least 200 cells were counted to obtain the average percentage of neutrophils.

\section{Measurement of plasma insulin and blood glucose}

Blood glucose was measured in freshly drawn blood by ACCUCHEK $^{\circ}$ Active ${ }^{\mathrm{TM}}$ blood glucose meter and test strips from Roche diagnostics GmbH (Mannheim, Germany). Plasma insulin assays were done as a batched analysis at the end of the study. Plasma insulin levels were determined using ELISA kit according to the manufacturer's instructions (cat. no. EZRMI-13K, Millipore Research (MA, USA).

\section{PK analysis}

Adult male Sprague-Dawley rats (IV and PO, $\mathrm{n}=2$ each arm per compound, aged approximately 6 weeks) were cannulated via jugular vein and carotid artery, and recovered for 3-5 days prior to the PK study. Test compounds were administered intravenously (via jugular vein cannula) or via PO route, respectively. Blood was collected via carotid cannula at different time points (IV: $0.083,0.25,0.5,1,2,4,6,8$, and $24 \mathrm{~h}$ post dose; PO: $0.25,0.5,0.75,1,2,4,6,8$, and $24 \mathrm{~h}$ post dose). Plasma concentrations were quantified by established LC-MS/MS with internal standard. The lower limit of quantification (LLOQ) of drug in plasma was $\leq 3 \mathrm{ng} / \mathrm{mL}$ using a $0.025 \mu \mathrm{L}$ plasma aliquot. Calibration standards were 1, 2, 10, 50, 100, 500, 1000 and $3000 \mathrm{ng} / \mathrm{mL}$. Fresh and stored quality control samples at 3, 800 and $2700 \mathrm{ng} / \mathrm{mL}$ (prepared in rat plasma and stored together with authentic samples) were included in each analysis to ensure assay performance.

\section{Results}

\section{Compound profiling}

Over 8800 patent, literature, company file library and singleton compounds were tested, as well as fragment screening (Hughes, S.J et al., manuscript in submission) and HTS hit follow up compounds. A schematic representation of the chemical space explored in these series is depicted in Figure 1. Over 98\% of these compounds exhibited no or less than 10x selectivity for Pi3K gamma over Pi3K alpha. A very small number of compounds had up to 20 fold selectivity, and one compound 35 fold. Poor solubility limiting absorption, and oxidative metabolic instability was a common theme amongst these compounds, preventing dose escalation in in vivo studies. However, we were able to design 3 fit for purpose tool compounds (Figure 2) with up to $6 \mathrm{x}$ selectivity over

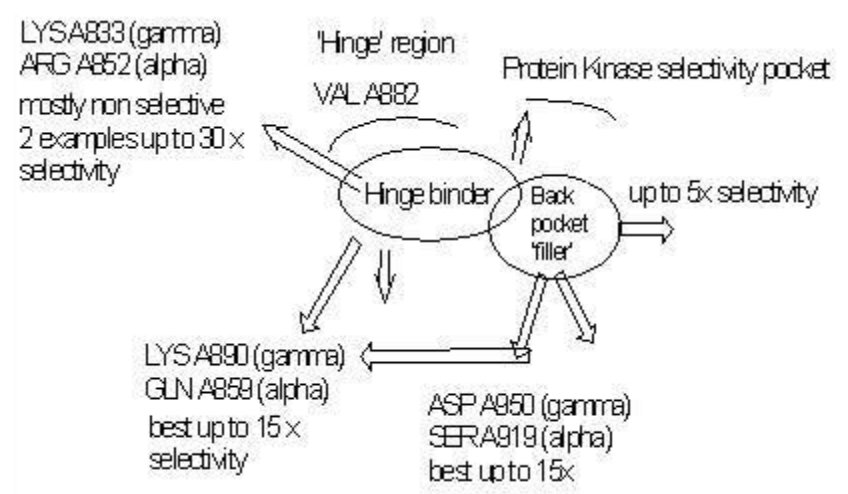

Figure 1: Schematic representation of regions of space explored by 8800 compounds, and best selectivities obtained in regions.

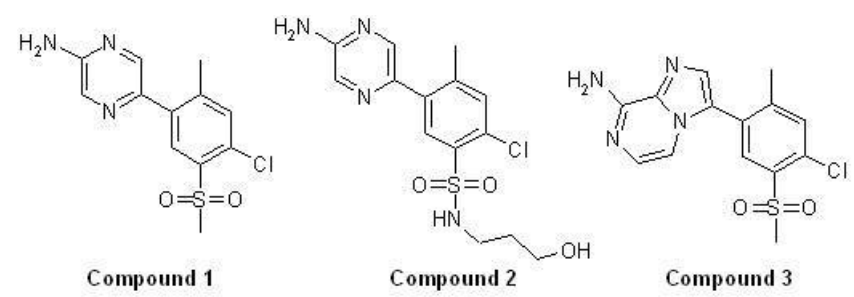

Figure 2: Chemical structure of compounds 1, 2 and 3. 
alpha with suitable in vitro and in vivo pharmacokinetics in rat to study a wide dose range in our in vivo model to investigate the in vitro to in vivo translation.

\section{Potency against human PI3K enzyme isoforms and human and rat IL-8 stimulated neutrophil shape change}

The potency for compounds 1, 2, and 3 against human $\mathrm{PI} 3 \mathrm{~K} \gamma$, $\mathrm{PI} 3 \mathrm{~K} \alpha, \mathrm{PI} 3 \mathrm{~K} \beta$ and PI3K $\delta$ is listed in Table 1. All 3 compounds showed a similar potency against the PI $3 \mathrm{~K} \gamma$ enzyme $(69-185 \mathrm{nM})$, and generally each were more selective for PI3K $\gamma$ over PI3K $\delta$, than for PI3K $\gamma$ over either PI3Ka or PI3K $\beta$; compound 1 was $1.5 \mathrm{x}, 5 \mathrm{x}$ and $6.5 \mathrm{x}$ fold selective for PI $3 \mathrm{~K} \gamma$ over PI3K $\delta$, PI3Ka and PI3K $\beta$ respectively, compound 3 was 5.9x, 25.9x and $16.9 \mathrm{x}$ fold selective for PI3K $\gamma$ over PI3K $\delta, \mathrm{PI} 3 \mathrm{Ka}$ and PI3K $\beta$ respectively, and compound 2 was $5.6 \mathrm{x}, 10.8 \mathrm{x}$ and $13.4 \mathrm{x}$ fold selective for $\mathrm{PI} 3 \mathrm{~K} \gamma$ over $\mathrm{PI} 3 \mathrm{~K} \delta$, PI3Ka and $\mathrm{PI} 3 \mathrm{~K} \beta$ respectively.

All 3 compounds exhibited similar potency against human (67-166 $\mathrm{nM})$ and rat $(582-826 \mathrm{nM})$ neutrophils in an IL-8 stimulated shapechange assay (Table 2), although all compounds were more potent in the human assay than the rat assay (between $4 \mathrm{x}$ and $11 \mathrm{x}$ more potent). This may be a consequence of different assay formats; the human assay used lysed whole blood, whereas the rat assay used unlysed whole blood. It is also possible that using human recombinant IL-8 as a stimulus for both human and rat assays may result in different sensitivity within each assay.

\section{Pharmacokinetics}

All 3 compounds were relatively well matched in terms of in vitro $\mathrm{PK}$ properties, demonstrating low rat hepatocyte clearance $(<5$ $\mu \mathrm{l} / \mathrm{min} / 10^{6}$ cells) and similar $\log \mathrm{D}_{74}$ values $(1.1-1.6)$ and aqueous solubilities $(209-278 \mu \mathrm{M})$ as shown in Table 3 . Compound 2 exhibited a lower cellular permeability $\left(7 \times 10^{-6} \mathrm{cms}^{-1}\right)$ compared with compounds $1\left(35 \times 10^{-6} \mathrm{cms}^{-1}\right)$ and $3\left(22 \times 10^{-6} \mathrm{cms}^{-1}\right)$.

\begin{tabular}{|c|c|c|c|c|}
\hline Compound & $\begin{array}{c}\text { Gamma } \\
\mathrm{IC}_{50}, \mathrm{nM}^{\mathrm{a}}\end{array}$ & $\begin{array}{c}\text { Alpha } \\
\mathrm{IC}_{50}, \mathrm{nM}^{\mathrm{a}}\end{array}$ & $\begin{array}{c}\text { Beta } \\
\mathrm{IC}_{50}, \mathrm{nM}^{\mathrm{a}}\end{array}$ & $\begin{array}{c}\text { Delta } \\
\mathrm{IC}_{50}, \mathrm{nM}^{\mathrm{a}}\end{array}$ \\
\hline 1 & 185 & 277 & 923 & 1210 \\
& $(120-287)$ & $(192-400)$ & $(612-1390)$ & $(735-1990)$ \\
\hline 2 & 69 & 389 & 742 & 927 \\
& $(46-104)$ & $(265-571)$ & $(489-1130)$ & $(693-1240)$ \\
\hline 3 & 114 & 678 & 2950 & 1930 \\
& $(91-142)$ & $(475-467)$ & $(2310-3780)$ & $(1460-2550)$ \\
\hline
\end{tabular}

avalues are geomeans of at least 8 experiments,

$95 \%$ confidence limits are given in parentheses.

Table 1: Human PI3K enzyme isoform inhibition by compounds 1, 2 and 3 .

\begin{tabular}{|c|c|c|}
\hline & \multicolumn{2}{|c|}{ IL-8-stimulated neutrophil shape change } \\
\hline Compound & $\begin{array}{c}\text { Human lysed blood } \\
I_{50}, \mathrm{nM}^{\mathrm{a}}\end{array}$ & $\begin{array}{c}\text { Rat whole blood } \\
\mathrm{IC}_{50}, \mathrm{nM}^{\mathrm{a}}\end{array}$ \\
\hline 1 & $67(\mathrm{n}=2)$ & $740(\mathrm{n}=5)$ \\
\hline 2 & $166(\mathrm{n}=2)$ & $826(\mathrm{n}=3)$ \\
\hline 3 & $139(\mathrm{n}=2)$ & $582(\mathrm{n}=2)$ \\
\hline
\end{tabular}

Table 2: Human and rat IL-8 stimulated neutrophil shape-change inhibition by compounds 1,2 , and 3 .

\begin{tabular}{|c|c|c|c|c|}
\hline Compound & $\begin{array}{c}\text { Rat Hepatocyte Clearance } \\
(\mu \mathrm{l} / \mathrm{min} / \text { million cells })\end{array}$ & $\log _{7.4}$ & $\begin{array}{c}\text { Aqueous } \\
\text { Solubility } \\
(\mu \mathrm{M})\end{array}$ & $\begin{array}{c}\text { RRCK } \\
\text { Permeability } \\
\text { Papp AB } \\
\left(\times 10^{-6} \mathrm{cms}^{-1}\right)\end{array}$ \\
\hline 1 & $<5$ & 1.6 & 229 & 35 \\
\hline 2 & $<5$ & 1.5 & 209 & 7 \\
\hline 3 & Not tested & 1.1 & 278 & 22 \\
\hline
\end{tabular}

Table 3: In vitro pharmacokinetic properties of compounds 1, 2 and 3.

\begin{tabular}{|c|c|c|c|c|}
\hline Compound & $\begin{array}{c}\text { Rat iv Total Clearance } \\
(\mathrm{ml} / \mathrm{min} / \mathrm{kg})\end{array}$ & $\begin{array}{l}\text { Oral Bioavailability } \\
\mathrm{F} \%\end{array}$ & $\begin{array}{c}\mathrm{T}_{1 / 2}^{\mathrm{a}, \mathrm{d}} \\
(\mathrm{hrs})\end{array}$ & $\begin{array}{c}\mathrm{Vdss}^{\mathrm{a}} \\
(\mathrm{L} / \mathrm{kg})\end{array}$ \\
\hline 1 & 8.7 & $\mathrm{n} / \mathrm{d}$ & 1.5 & 1.1 \\
\hline 2 & 49 & 35 & 0.45 & 1.86 \\
\hline 3 & 24 & 100 & 2.2 & 4.63 \\
\hline
\end{tabular}

aValues are means of 2 rats,

${ }^{\mathrm{b}}$ From $1 \mathrm{mg} / \mathrm{kg}$ i.v. dose

${ }^{\mathrm{c}}$ From $10 \mathrm{mg} / \mathrm{kg}$ oral dose

dFrom i.v. PK studies

Table 4: In vivo rat pharmacokinetic properties of compounds 1, 2 and 3 .

The in vivo pharmacokinetic properties of the 3 compounds are listed in Table 4. Compound 2 exhibited the greatest total clearance of $49 \mathrm{ml} / \mathrm{min} / \mathrm{kg}$ and compound 1 the lowest $(8.7 \mathrm{ml} / \mathrm{min} / \mathrm{kg})$, although none approached the liver blood flow clearance value in rat of $70 \mathrm{ml} /$ $\mathrm{min} / \mathrm{kg}$ ). Plasma profiles for each compound following an oral dose are shown in Figure 3a. The compound exposure in the 6 hour time period between dosing, LPS challenge and euthanasia is relatively stable. Increasing oral doses resulted in a dose-dependent increase in plasma concentrations (Figure $3 \mathrm{~b}$ ), with compounds 1 and 2 exceeding the rat whole cell $\mathrm{IC}_{50}$ at a dose of approximately $3 \mathrm{mg} / \mathrm{kg}$ and compound 3 exceeding the rat whole cell $\mathrm{IC}_{50}$ at approximately $100 \mathrm{mg} / \mathrm{kg}$.

\section{Inhibition of LPS-elicited pulmonary neutrophilia and} changes in serum insulin \& glucose concentrations

Instillation of LPS into the trachea resulted in a marked increase in airway neutrophils 5 hours post challenge $\left(0.2 \pm 0.0 \times 10^{6}\right.$ (saline) vs 5.6 $\pm 0.8 \times 10^{6}$ (LPS) neutrophils/ml BAL; $P<0.001$ ). Oral pre-treatment with suspensions of Compounds 1, 2 and 3 resulted in a dose- and blood concentration- dependent inhibition of neutrophilia. The calculated $\mathrm{EC}_{50}$ values are listed in Table 5. The maximal inhibition of neutrophilia achieved for the 3 compounds was $96.6 \%, 94.5 \%$ and $95.3 \%$ which was greater than observed with $10 \mathrm{mg} / \mathrm{kg}$ p.o. prednisolone (87.5\%). Whilst the rank order of potency against inhibition of neutrophilia appeared to be Compound $2>$ Compound $1>$ Compound 3 , there was no statistically significant differences between them.

Increases in blood glucose and plasma insulin were also observed at the higher dose and blood concentration levels of all 3 compounds. $\mathrm{EC}_{50}$ values are listed in Table 5. Plasma insulin appeared to be a more sensitive index, with elevations being at observed in lower dose groups and at lower blood concentrations of compound compared with the blood glucose measurement.

The preclinical therapeutic index was calculated for each compound by dividing the $\mathrm{EC}_{50}$ value for changes in either blood glucose or plasma insulin by the $\mathrm{EC}_{50}$ value for inhibition of neutrophilia (Table 5). The relationship between these parameters is also shown in figure 4 . The rank order of therapeutic index for these compounds was Compound $1>$ Compound 2> Compound 3. This was consistent when calculated for changes in either blood glucose or plasma insulin. However, it is not consistent with the rank order of potency, suggesting that differences in selectivity profile of these compounds may influence the therapeutic index for each.

\section{Discussion}

Various publications [8,9] have suggested a degree of selectivity of ligands between the Pi3K isoforms; in some cases the $\mathrm{IC}_{50}$ 's compared are derived from assays using different concentrations of ATP. We were keen to investigate the selectivity of compounds across the Pi3K isoforms using the same concentration of ATP in assays to provide a fair test of selectivity. We have investigated 8800 compounds which 
Citation: Lamb D, Lunn G, O’Reilly M, Butler C, Kilty I (2013) In vitro and In vivo Assessment of Pi3Ky Inhibitors for Anti-Inflammatory Indications:

(a)

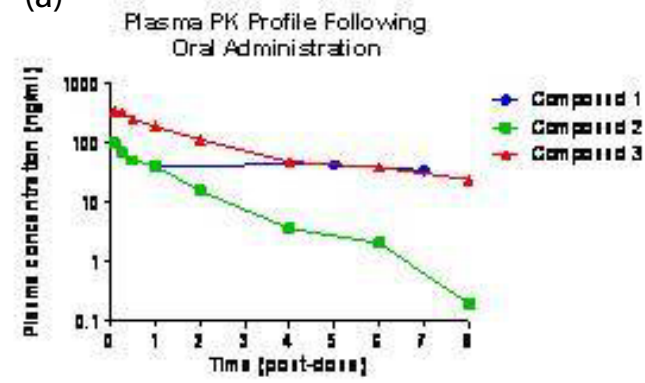

(b)
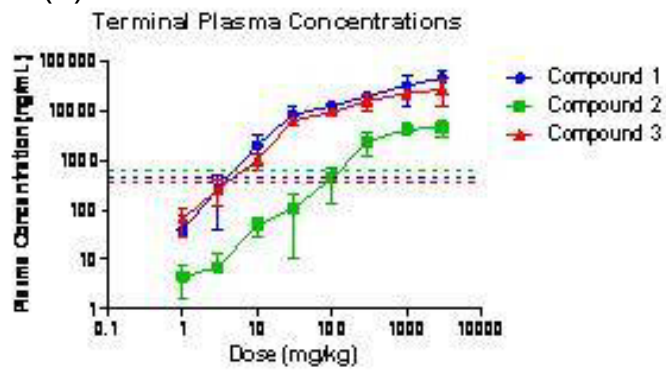

Figure 3: Plasma PK profiles of compounds 1, 2 and 3

Rats were dosed orally with compound 1,2 and 3 and plasma concentrations (normalised to a $1 \mathrm{mg} / \mathrm{kg}$ oral dose) plotted over time (a). Terminal plasma samples from the efficacy study are also plotted by dose group (b). The rat whole cell IC ${ }_{50}$ values for each compound are represented by the dashed line

\begin{tabular}{|c|c|c|c|}
\hline & Compound 1 & Compound 2 & Compound 3 \\
\hline $\begin{array}{l}\text { Neutrophil Inhibition }{ }^{\mathrm{a}} \\
\mathrm{EC}_{50}(95 \% \mathrm{Cl})\end{array}$ & $\begin{array}{c}401 \mathrm{ng} / \mathrm{ml} \\
(83-1928)\end{array}$ & $\begin{array}{l}94 \mathrm{ng} / \mathrm{ml} \\
(24-400)\end{array}$ & $\begin{array}{c}1062 \mathrm{ng} / \mathrm{ml} \\
(379-2970)\end{array}$ \\
\hline $\begin{array}{l}\text { Plasma Insulin Elevation } \\
\mathrm{EC}_{50}(95 \% \mathrm{Cl})\end{array}$ & $\begin{array}{c}6648 \mathrm{ng} / \mathrm{ml} \\
(3379-13082)\end{array}$ & $\begin{array}{c}1220 \mathrm{ng} / \mathrm{ml} \\
(585-2546)\end{array}$ & $\begin{array}{c}2027 \mathrm{ng} / \mathrm{ml} \\
(929-4421)\end{array}$ \\
\hline Neutrophil vs Insulin therapeutic index ${ }^{b}$ & 16.6 & 13.0 & 1.9 \\
\hline $\begin{array}{l}\text { Blood Glucose Elevation }{ }^{a} \\
\mathrm{EC}_{50}(95 \% \mathrm{Cl})\end{array}$ & $\begin{array}{c}19641 \mathrm{ng} / \mathrm{ml} \\
(13541-28490)\end{array}$ & $\begin{array}{c}2649 \mathrm{ng} / \mathrm{ml} \\
(1438-4879)\end{array}$ & $\begin{array}{c}13847 \mathrm{ng} / \mathrm{ml} \\
(11992-15989)\end{array}$ \\
\hline Neutrophil vs Glucose therapeutic index & 49.0 & 28.2 & 13.0 \\
\hline
\end{tabular}

${ }^{a} \mathrm{EC}_{50}$ values calculated from plotting individual curves for neutrophil inhibition, glucose and insulin endpoints against the individual plasma concentrations of each compound for each of 54 animals ( 9 dose groups of $n=6$ ).

${ }^{\mathrm{b}}$ Therapeutic index values calculated by dividing the $\mathrm{EC}_{50}$ value for glucose or insulin endpoints by the $\mathrm{EC}_{50}$ value for neutrophil inhibition endpoint

Table 5: Calculated $\mathrm{EC}_{50}$ values for the inhibition of LPS-elicited neutrophilia and changes in plasma insulin and blood glucose following treatment with compounds 1,2 and 3 and calculated therapeutic index for each compound.

(a)

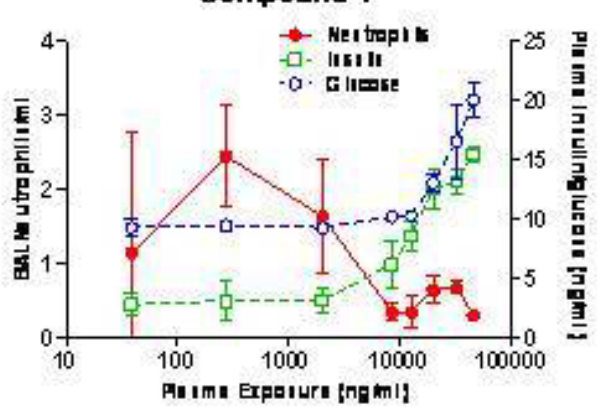

(b) Compound 2

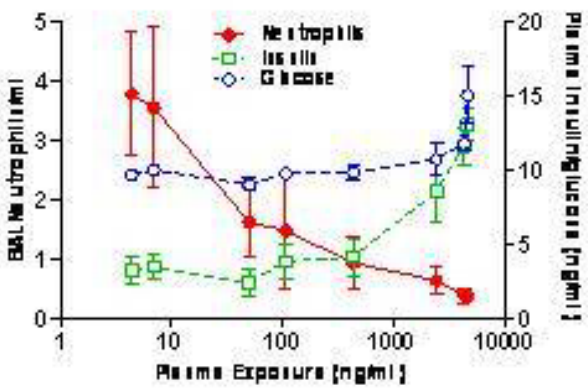

(c)

Compound 3

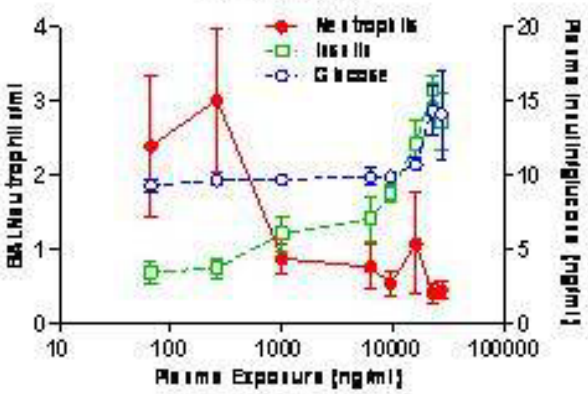

Figure 4: Inhibition of LPS-elicited neutrophilia and changes in plasma insulin and blood glucose following treatment with Compounds 1,2 and 3 Rats were pre-dosed with compound orally 1 hour prior to lung LPS challenge. Five hours post-challenge, blood samples were collected and the lungs lavaged. The inhibition of LPS-elicited neutrophilia, combined with plasma levels of insulin and blood levels of glucose are plotted against serum concentrations of (a) compound 1 , (b) compound 2, and (c) compound 3. Each point in the geometric mean \pm SEM of 6 animals. 
represent a broad diversity of over 25 different ATP competitive hinge binding chemotypes, including several literature compounds previously reported as having a degree of selectivity or Pi3K gamma over Pi3K alpha. As we were testing at the same concentration of ATP across the $\mathrm{Pi} 3 \mathrm{~K}$ isoforms, in all cases literature compound gave selectivities over alpha lower than that reported.

For example, Camps et al. [8] discuss PI3K isoform $\mathrm{IC}_{50}$ data derived from an assay which uses an ATP concentration of $21 \mu \mathrm{M}$ for the gamma isoform, and $90 \mu \mathrm{M}$ ATP for the alpha isoform assay. This 4.3 fold difference in substrate concentration would naturally produce a similar shift when comparing inhibition concentration curves. In the paper, compound AS-604850 is described as being $18 \mathrm{x}$ selective for gamma over alpha, and compound AS-605240 is described as 7.5x selective. In our assay the final ATP concentration used in all 4 PI3K enzyme assays was the same $-20 \mathrm{uM}$. Thus when comparing the data from Rommel et al. [1], one would expect to observe a selectivity value of 4.3 times less. In our assay, no significant selectivity for Pi3K gamma over Pi3K alpha was observed for both AS-604850 and AS-605240 (data not shown).

Despite exhaustively probing space in the ATP binding pocket (confirmed with several co-crystal structures with the Pi3K gamma active site) over $98 \%$ of these compounds exhibited no or less than 10x selectivity for Pi3K gamma over Pi3K. A very small number of our compounds had up to 20-fold selectivity, and one compound 35-fold, however poor solubility limiting absorption, and oxidative metabolic instability was a common theme amongst these compounds, preventing dose escalation in in vivo studies. Thus, the overlap of potency, greater than $5 \mathrm{x}$ selectivity and good drug space was indeed a challenge. However as described above, our fit for purpose tool compounds did enable in vivo dosing to enable translation from in vitro data.

A novel rat model was developed and characterised that enable simultaneous assessment of Pi3Kgamma mediated efficacy and Pi3Kalpha driven perturbations in glucose/insulin homeostasis in the same animal. This enabled the determination of a pre-clinical therapeutic index with the additional benefits of reducing both animal numbers and the variability in data that would be attributed to dosing separate animals for different end points. Similar models have been described in the literature to assess other mechanisms, for exampleinhaled corticosteroids (efficacy versus HPA axis suppression) [10].

The therapeutic index values in this report were derived objectively from calculated $\mathrm{EC}_{50}$ values. Subjective observations from the relationship between these parameter profiles suggest that, at least for Compound 1 and Compound 2, maximal inhibition of neutrophilia coincides with the beginnings of increases in blood glucose and plasma insulin. Calculated using these criteria, the therapeutic index for these 2 compounds would be one. Compound 3; however, appears to exert maximal inhibition of neutrophilia at blood concentrations which are not associated with changes in either blood glucose or plasma insulin, suggesting a therapeutic index greater than one. The differences between the objective and subjectively derived therapeutic index probably reflects differences in the slope of the curves; for the inhibition of neutrophilia endpoint, Compound 1 and Compound 2 exhibit relatively shallow dose response curves, and hence quite different $\mathrm{EC}_{50}$ and $\mathrm{EC}_{80}$ values, whereas Compound 3 demonstrates a much steeper dose-response against and therefore quite similar $\mathrm{EC}_{50}$ and $\mathrm{EC}_{80}$ values.

\section{Conclusion}

In our opinion, these studies provide no evidence of a divergence from enzyme selectivity to an in vivo therapeutic index over insulin and glucose pertubations. After testing 8800 compounds from 25 chemotypes, there is no evidence to suggest ATP competitive hinge binding site PI3Kgamma inhibitors will afford sufficient in vivo TI worthy of clinical progression for inflammatory indications.

\section{References}

1. Rückle T, Schwarz MK, Rommel C (2006) PI3Kgamma inhibition: towards an 'aspirin of the 21st century'? Nat Rev Drug Discov 5: 903-918.

2. Kong D, Yamori T (2008) Phosphatidylinositol 3-kinase inhibitors: promising drug candidates for cancer therapy. Cancer Sci 99: 1734-1740.

3. Thomas M, Owen C (2008) Inhibition of Pl-3 kinase for treating respiratory disease: good idea or bad idea? Curr Opin Pharmacol 8: 267-274.

4. Vanhaesebroeck B, Guillermet-Guibert J, Graupera M, Bilanges B (2010) The emerging mechanisms of isoform-specific PI3K signalling. Nat Rev Mol Cell Biol 11: 329-341.

5. Takeda M, Ito W, Tanabe M, Ueki S, Kihara J, et al. (2010) The pathophysiologica roles of PI3Ks and therapeutic potential of selective inhibitors in allergic inflammation. Int Arch Allergy Immunol 152 Suppl 1: 90-95.

6. Lannutti BJ, Meadows SA, Herman SE, Kashishian A, et al. (2011) CAL-101, a p110delta selective phosphatidylinositol-3-kinase inhibitor for the treatment of $\mathrm{B}$-cell malignancies, inhibits $\mathrm{PI} \mathrm{K}$ signaling and cellular viability. Blood 117 591-594.

7. Knight ZA, Gonzalez B, Feldman ME, Zunder ER, Goldenberg DD, et al. (2006) A pharmacological map of the PI3-K family defines a role for p110alpha in insulin signaling. Cell 125: 733-747.

8. Camps M, Rückle T, Ji H, Ardissone V, Rintelen F, et al. (2005) Blockade of PI3K? suppresses joint inflammation and damage in mouse models of rheumatoid arthritis. Nat. Med 11: 936-943.

9. Pomel V, Klicic J, Covini D, Church DD, Shaw JP, et al. (2006) Furan-2 ylmethylene Thiazolidinediones as Novel, Potent, and Selective Inhibitors of Phosphoinositide 3-Kinase gamma. J Med Chem 49: 3857-3871.

10. Chiang PC, Hu Y, Thurston A, Sommers CD, Guzova JA, et al. (2009) Pharmacokinetic and pharmacodynamic evaluation of the suitability of using fluticasone and an acute rat lung inflammation model to differentiate lung versus systemic efficacy. J Pharm Sci 98: 4354-4364. 